\title{
Qualidade microbiológica da água para consumo humano em unidades de
}

$$
\text { alimentação escolar }
$$

\author{
Tatiane FARIA ${ }^{1}$ \\ Ramon Alves de Oliveira PAULA ${ }^{2}$ \\ ${ }^{1}$ Graduanda em Nutrição, UNIFAL-MG (Universidade Federal de Alfenas) \\ Sandra Maria Oliveira Morais VEIGA ${ }^{3}$ \\ ${ }^{2}$ Graduando em Farmácia, UNIFAL-MG \\ ${ }^{3}$ Professora Doutora da UNIFAL-MG \\ Faculdade de Ciências Farmacêuticas / Faculdade de Nutrição - Universidade Federal de Alfenas \\ *tatianefaria_tf@yahoo.com.br
}

Recebido em: 02/05/2013 - Aprovado em: 15/07/2013 - Disponibilizado em: 15/08/2013

\section{RESUMO}

Considerando que as crianças passam grande parte do dia na escola, é de fundamental importância avaliar a potabilidade da água de consumo, pois ela é utilizada para hidratação, bem como em todas as atividades de higiene e no preparo de alimentos. Ainda, muitas escolas não realizam a manutenção e higienização adequada de seus reservatórios de água, o que pode gerar a contaminação. No caso de instituições educacionais, a preocupação com as doenças veiculadas por água e alimentos (DVA) deve ser rigorosa já que se deve considerar que, as crianças, principalmente as mais novas, são muito susceptíveis às toxinfecções alimentares. O consumo de água contaminada pode levar ao desenvolvimento de várias doenças, entre elas a diarréia, que gera comprometimento do estado geral da criança, além de afetar seu desenvolvimento escolar. Assim, este trabalho teve como objetivo avaliar a qualidade microbiológica da água de abastecimento de unidades de alimentação de escolas públicas do município de Alfenas - MG. Foram realizadas análises microbiológicas (Aeróbios Mesófilos, Coliformes Totais e Escherichia coli) e químicas (pH e cloro), utilizando valores de referência da legislação vigente. Foram analisadas 63 amostras, sendo que 14\% apresentaram contaminação. Os resultados também demonstraram a importância de se monitorar a qualidade da água, e adoção de medidas de caráter preventivo e corretivo.

Palavras-chave: Água. Escola. Criança. Microbiologia. Monitoramento.

\section{Microbiological quality water for human consumption in units supply school} \begin{abstract}
Considering that children spend much of their day at school, is very important to evaluate the potability of drinking water because it is used for hydration, as well in all hygiene activities and food preparation. Furthermore, many schools do not perform proper maintenance and cleaning of their water reservoirs, which can cause contamination. In the case of educational institutions, the worry with diseases related to water and food (DVA) must be rigorous since should be assumed that children, especially the younger ones, are very susceptible to food intoxication. The contaminated water consumption can lead to the development of several diseases, including diarrhea, which causes general commitment of the child health, besides affecting its school development. This study aimed to evaluate the microbiological quality of food establishment water supply of public schools in Alfenas - MG. Microbiological analyzes were performed (Aerobic Mesophilic, Total Coliforms and Escherichia coli) and chemical ( $\mathrm{pH}$ and chlorine), using reference values of legislation. 63 samples were analyzed, in which $14 \%$ were contaminated. The results also demonstrated the importance of monitoring water quality, and adopting preventive and corrective measures.
\end{abstract}

Keywords:.Water. School. Child. Microbiology. Monitoring.

\section{INTRODUÇÃO}

Essencial à manutenção da vida, a água constitui um recurso de extrema importância para os seres vivos (CRUZ et al 2009). Seus

diversos usos são indispensáveis para
inúmeras atividades, como a irrigação


agrícola, o abastecimento público e de indústrias, o transporte, produção de energia elétrica, as atividades de recreação, preservação da vida aquática entre outras (GUILHERME et al., 2000). Porém, a água contaminada é capaz de veicular agentes infecciosos ou substâncias capazes de agredir a saúde humana (SCHAZMANN et al, 2008).

Conforme Caubet (2006), nos países mais pobres, cerca de dois milhões de pessoas morrem anualmente devido a doenças gastrintestinais decorrentes da falta de água tratada, sendo que crianças constituem a maior parcela dessa estatística. Estima-se que cerca de $70 \%$ dos leitos hospitalares estejam ocupados por pessoas que contraíram doenças transmitidas por água contaminada (JUNIOR, 2007).

No caso de instituições educacionais, a preocupação com as doenças veiculadas por água e alimentos (DVA) deve ser rigorosa, já que as crianças, principalmente as mais novas, são muito susceptíveis às toxinfecções alimentares e dependendo da gravidade do caso, podem até evoluir para o óbito. Assim, alunos, professores e funcionários poderão adquirir uma doença de origem hídrica/alimentar no ambiente escolar, caso as regras básicas de higiene não sejam rigorosamente observadas (SILVA, 2006).

Muitas crianças têm a alimentação escolar como sua refeição diária principal, porém diversas escolas não possuem um programa de higienização adequado dos reservatórios de água. Estes acabam permanecendo por longos períodos sem nenhum tipo de manutenção ou tratamento. Por conseqüência, pode ocorrer ingestão de alimentos contaminados, já que essa água é utilizada nas preparações alimentícias, podendo causar algum tipo de toxinfecção alimentar (ROCHA, et al., 2010).

A freqüência escolar pode aumentar se as condições sanitárias da unidade de ensino sofrerem melhorias. Segundo Serra et al., (2012), é habitual no Brasil a ocorrência de escolas funcionando com instalações que deixam a desejar, equipamentos e instalações deficientes, sem abastecimento hídrico ou com água não potável. Este fato é muito preocupante, pois os alunos passam cerca de um terço de seus dias nas escolas, podendo estas instituições influenciarem diretamente na saúde dos mesmos (CASALI, 2008).

Sabe-se que além da poluição direta das fontes de água e dos sistemas de distribuição, as condições higiênico-sanitárias e conservação dos reservatórios também podem ser responsáveis pela veiculação de agentes patogênicos, pois assumem papel importante na contaminação ou recontaminação da água. Isso ocorre pela transmissão de micro-organismos caso estes locais estejam em condições inadequadas de higiene e conservação (MICHELINA et al., 2006).

Considerando os fatos acima expostos, este estudo teve por objetivo avaliar a 
qualidade microbiológica da água de abastecimento de unidades de alimentação escolar do município de Alfenas - MG.

\section{MATERIAIS E MÉTODOS}

O estudo ocorreu entre os meses de agosto a setembro de 2012. Foram coletadas conforme normas de assepsia, 63 amostras de água em 21 escolas públicas municipais. As coletas foram realizadas em três diferentes pontos por escola sendo eles: bebedouro/filtro, torneira da cozinha $\mathrm{e}$ torneira da área externa.

A coleta e os ensaios realizados seguiram metodologias descritas por Silva et al (2010).

Iniciava-se a coleta com a desinfecção da torneira ou ponto de água com álcool. Posteriormente, sob condições assépticas e com auxílio de um campo de chama acionavase a torneira e aguardavam-se de 2 a 3 minutos para o escoamento da água, em seguida, coletavam-se $200 \mathrm{~mL}$ em frascos estéreis contendo tiossulfato de sódio para a neutralização do cloro residual.

Como informações adicionais e diretamente relacionadas com a qualidade microbiológica da água, foram determinados cloro e o $\mathrm{pH}$ nos pontos de coleta, utilizandose respectivamente Kit Micro Quanti e tiras reagentes, ambos marca Merck ${ }^{\circledR}$.

As amostras foram identificadas, acondicionadas em caixas isotérmicas contendo gelo e transportadas até ao laboratório de Microbiologia de Alimentos da Universidade Federal de Alfenas-MG, aonde se conduziram os ensaios.

Foram pesquisados os seguintes micro-organismos: Coliformes Totais (Coliformes a $\left.\quad 35^{\circ} \mathrm{C}\right), \quad$ Coliformes termotolerantes (Escherichia coli) e bactérias heterotróficas aeróbias mesofílicas, utilizando-se como parâmetro de potabilidade a Portaria $n^{\circ} 2.914$ do Ministério da Saúde (BRASIL, 2011).

\section{RESULTADOS E DISCUSSÃO}

De acordo com a figura 1, observa-se que entre as 63 amostras estudadas, 9 (14\%) apresentaram inadequação do ponto de vista microbiológico, conforme legislação vigente (Brasil, 2011), devido a presença de Coliformes Totais, E. coli e/ou alta contagem de bactérias heterotróficas (Gráfico1).

Estudo semelhante realizada por Neto et al (2006) identificaram, ao avaliar a água de escolas públicas do Recife (PE), que 37\% das amostras apresentaram-se impróprias de acordo com os padrões de potabilidade.

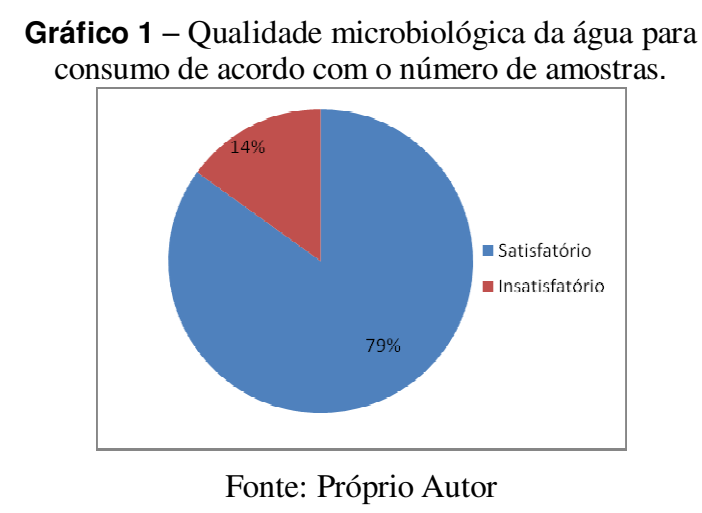


Pode-se constatar que 7 instituições apresentaram resultados positivos para coliformes totais. A presença destes microorganismos numa amostra de água para consumo é suficiente para sua reprovação, sem a necessidade de que se obtenha resultado positivo na pesquisa de Coliformes termotolerantes, conforme ressalta a Portaria no 2914 do Ministério da Saúde. Assim, segundo os critérios de potabilidade, a presença de coliformes totais na água, torna-a imprópria para consumo humano.

Observou-se contaminação por Escherichia coli em 1 escola. Todos os resultados encontram-se dispostos nos quadros $1,2,3$ e 4 .

Quadro 1- Qualidade microbiológica e química das amostras de água provenientes da torneira da cozinha.

\begin{tabular}{|c|c|c|c|c|c|c|}
\hline \multirow[b]{2}{*}{ ESCOLAS } & \multicolumn{5}{|c|}{$\begin{array}{l}\text { Local: TORNEIRA DA COZINHA } \\
\text { Parâmetros Pesquisados }\end{array}$} & \multirow[b]{2}{*}{ RESULTADO FINAL } \\
\hline & $\begin{array}{c}\text { Aeróbios } \\
\text { Mesófilos } \\
\text { (UFC/mL) }\end{array}$ & $\begin{array}{c}\text { Coliformes } \\
\text { Totais } \\
(\mathrm{NMP} / 100 \mathrm{~mL})\end{array}$ & $\begin{array}{c}\text { Escherichia } \\
\text { coli } \\
(\mathrm{NMP} / 100 \mathrm{~mL})\end{array}$ & pH & Cloro & \\
\hline $\mathrm{A}$ & Ausente & Ausente & Ausente & 7,0 & 0 & Aprovado \\
\hline $\mathrm{B}$ & Ausente & Ausente & Ausente & 7,8 & 2,0 & Aprovado \\
\hline $\mathrm{C}$ & 4 & Ausente & Ausente & 6,8 & 1,0 & Aprovado \\
\hline $\mathrm{D}$ & 4 & Ausente & Ausente & 7,0 & 0 & Aprovado \\
\hline$E$ & 3 & Ausente & Ausente & 7,0 & 0,4 & Aprovado \\
\hline $\mathrm{F}$ & Ausente & Ausente & Ausente & 7,0 & 1,5 & Aprovado \\
\hline $\mathrm{G}$ & Ausente & Ausente & Ausente & 7,0 & 2,0 & Aprovado \\
\hline $\mathrm{H}$ & Ausente & Ausente & Ausente & 7,0 & 2,0 & Aprovado \\
\hline I & Ausente & Ausente & Ausente & 7,0 & 2,0 & Aprovado \\
\hline $\mathrm{J}$ & Ausente & 1 & Ausente & 7,0 & 2,0 & Reprovado \\
\hline $\mathrm{K}$ & Ausente & Ausente & Ausente & 7,0 & 2,0 & Aprovado \\
\hline $\mathrm{L}$ & Ausente & Ausente & Ausente & 7,0 & 0,6 & Aprovado \\
\hline $\mathrm{M}$ & Ausente & Ausente & Ausente & 7,0 & 2,0 & Aprovado \\
\hline $\mathrm{N}$ & Ausente & Ausente & Ausente & 7,0 & 1,0 & Aprovado \\
\hline $\mathrm{O}$ & Ausente & Ausente & Ausente & 7,0 & 0,8 & Aprovado \\
\hline $\mathrm{P}$ & Ausente & Ausente & Ausente & 6,8 & 2,0 & Aprovado \\
\hline $\mathrm{Q}$ & 1 & Ausente & Ausente & 7,0 & 1,5 & Aprovado \\
\hline $\mathrm{R}$ & 4 & Ausente & Ausente & 7,0 & 1,5 & Aprovado \\
\hline$S$ & Ausente & Ausente & Ausente & 7,0 & 1,0 & Aprovado \\
\hline $\mathrm{T}$ & Ausente & Ausente & Ausente & 6,8 & 0 & Aprovado \\
\hline $\mathrm{U}$ & 10 & 12,2 & Ausente & 7,0 & 0 & Reprovado \\
\hline
\end{tabular}

Fonte: Próprio Autor

UFC: Unidades Formadoras de Colônias

NMP: Número Mais Provável 
Quadro2- Qualidade microbiológica e química das amostras de água provenientes da rede de abastecimento (torneira externa).

\begin{tabular}{|c|c|c|c|c|c|c|}
\hline \multirow{2}{*}{ ESCOLAS } & \multicolumn{5}{|c|}{$\begin{array}{c}\text { Local: TORNEIRA EXTERNA } \\
\text { Parâmetros Pesquisados }\end{array}$} & \multirow{2}{*}{ RESULTADO FINAL } \\
\cline { 2 - 6 } & $\begin{array}{c}\text { Aeróbios } \\
\text { Mesófilos } \\
\text { (UFC'/mL) }\end{array}$ & $\begin{array}{c}\text { Coliformes } \\
\text { Totais } \\
\text { (NMP'/100mL) }\end{array}$ & $\begin{array}{c}\text { Escherichia } \\
\text { coli } \\
\text { (NMP/100mL) }\end{array}$ & pH & Cloro & \\
\hline A & Ausente & Ausente & Ausente & 7,0 & 3,0 & Aprovado \\
\hline B & Ausente & Ausente & Ausente & 4,0 & 2,0 & Aprovado \\
\hline C & Ausente & Ausente & Ausente & 7,0 & 1,5 & Aprovado \\
\hline E & Ausente & Ausente & Ausente & 7,0 & 2,0 & Aprovado \\
\hline F & Ausente & 2 & Ausente & 7,0 & 2,0 & Reprovado \\
\hline G & Ausente & Ausente & Ausente & 7,0 & 2,0 & Aprovado \\
\hline H & Ausente & Ausente & Ausente & 7,0 & 2,0 & Aprovado \\
\hline I & Ausente & 1 & Ausente & 7,0 & 2,0 & Reprovado \\
\hline J & Ausente & Ausente & Ausente & 7,0 & 2,0 & Aprovado \\
\hline K & 2 & Ausente & Ausente & 7,0 & 2,0 & Aprovado \\
\hline L & Ausente & Ausente & Ausente & 6,8 & 0,4 & Aprovado \\
\hline M & Ausente & Ausente & Ausente & 7,0 & 2,0 & Aprovado \\
\hline N & Ausente & Ausente & Ausente & 7,0 & 1,0 & Aprovado \\
\hline O & Ausente & 3,1 & Ausente & 7,0 & 0,2 & Reprovado \\
\hline P & Ausente & Ausente & Ausente & 6,8 & 2,0 & Aprovado \\
\hline Q & Ausente & Ausente & Ausente & 7,0 & 1,5 & Aprovado \\
\hline R & Ausente & Ausente & Ausente & 7,0 & 3,0 & Aprovado \\
\hline
\end{tabular}

Fonte: Próprio Autor

Quadro3- Qualidade microbiológica e química das amostras de água provenientes de bebedouros.

\begin{tabular}{|c|c|c|c|c|c|c|}
\hline \multirow{2}{*}{ ESCOLAS } & \multicolumn{5}{c|}{$\begin{array}{c}\text { Local: BEBEDOURO AÇO } \\
\text { Parâmetros Pesquisados }\end{array}$} & \multirow{2}{*}{ RESULTADO FINAL } \\
\cline { 2 - 6 } & $\begin{array}{c}\text { Aeróbios } \\
\text { Mesófilos } \\
\text { (UFC/mL) }\end{array}$ & $\begin{array}{c}\text { Coliformes } \\
\text { Totais } \\
\text { (NMP/100mL) }\end{array}$ & $\begin{array}{c}\text { Escherichia } \\
\text { coli } \\
\text { (NMP/100mL) }\end{array}$ & pH & Cloro & \\
\hline A & 14 & Ausente & Ausente & 7,0 & 0 & Aprovado \\
\hline B & Ausente & Ausente & Ausente & 7,4 & 0 & Aprovado \\
\hline C & 2 & Ausente & Ausente & 6,8 & 1,0 & Aprovado \\
\hline F & 10 & Ausente & Ausente & 7,0 & 0,2 & Aprovado \\
\hline G & Ausente & Ausente & Ausente & 9,0 & 0 & Aprovado \\
\hline I & Ausente & 1 & Ausente & 7,6 & 2,0 & Reprovado \\
\hline J & Ausente & Ausente & Ausente & 7,0 & 0,2 & Aprovado \\
\hline K & Ausente & Ausente & Ausente & 7,0 & 2,0 & Aprovado \\
\hline L & Ausente & Ausente & Ausente & 7,0 & 0,2 & Aprovado \\
\hline M & Ausente & Ausente & Ausente & 7,0 & 2,0 & Aprovado \\
\hline N & Ausente & Ausente & Ausente & 6,8 & 1,0 & Aprovado \\
\hline O & Ausente & Ausente & Ausente & 7,0 & 0,2 & Aprovado \\
\hline P & Ausente & Ausente & Ausente & 6,8 & 0,4 & Aprovado \\
\hline Q & Ausente & Ausente & Ausente & 7,0 & 0,4 & Reprovado \\
\hline R & Ausente & 8,6 & Ausente & 7,0 & 2,0 & Aprovado \\
\hline S & Ausente & Ausente & Ausente & 7,0 & 1,0 & Aprovado \\
\hline S & Ausente & Ausente & Ausente & 7,0 & 1,0 & Aprovado \\
\hline T & Ausente & Ausente & Ausente & 6,8 & 0 & Aprovado \\
\hline T** & Ausente & Ausente & Ausente & 7,0 & 0 & 0 \\
\hline U & $2,6 x 10^{4}$ & 5,2 & Ausente & 8,0 & 0 & Reprovado \\
\hline U* & 10 & 9,8 & Ausente & 7,0 & 0 & \\
\hline
\end{tabular}

Fonte: Próprio Autor 
Quadro 4- Qualidade microbiológica e química das amostras de água provenientes de filtros de barro.

\begin{tabular}{|c|c|c|c|c|c|c|}
\hline \multirow[b]{2}{*}{ ESCOLAS } & \multicolumn{5}{|c|}{$\begin{array}{l}\text { Local: FILTRO DE BARRO } \\
\text { Parâmetros Pesquisados }\end{array}$} & \multirow[b]{2}{*}{ RESULTADO FINAL } \\
\hline & $\begin{array}{l}\text { Aeróbios } \\
\text { Mesófilos } \\
\text { (UFC/mL) }\end{array}$ & $\begin{array}{c}\text { Coliformes } \\
\text { Totais } \\
(\mathrm{NMP} / 100 \mathrm{~mL})\end{array}$ & $\begin{array}{c}\text { Escherichia } \\
\text { coli } \\
(\mathrm{NMP} / 100 \mathrm{~mL}) \\
\end{array}$ & $\mathbf{p H}$ & Cloro & \\
\hline $\mathrm{D}$ & Ausente & Ausente & Ausente & 7,0 & 0 & Aprovado \\
\hline $\mathrm{E}$ & 1 & Ausente & Ausente & 7,0 & 0,4 & Aprovado \\
\hline $\mathrm{H}^{*}$ & Ausente & Ausente & Ausente & 7,0 & 0,6 & Aprovado \\
\hline $\mathrm{T}$ & $1,3 \times 10^{4}$ & $>2419,6$ & 1 & 7,0 & 0 & Aprovado \\
\hline
\end{tabular}

Fonte: Próprio Autor

*Filtro de plástico **Bebedouro com torneira de plástico

D, U, T: Água proveniente de poço artesiano

Sabe-se que entre as infecções entéricas, $25 \%$ podem ser atribuídas a três agentes bacterianos e seus diferentes sorotipos, sendo a E.coli um exemplo desses agentes. A presença desta enterobactéria na água deve ser avaliada, já que ela é um indicador de contaminação fecal sugerindo condições sanitárias insuficientes. Outro aspecto a ser considerado é a patogenicidade para o homem e para animais (FRANCO; LANDGRAF, 2006). Algumas linhagens patogênicas podem causar diarréia, febre, cólica, dentre outras (MICHELINA et al., 2006).

Num estudo realizado por Rocha et al (2010) em 36 escolas do município de Teixeira de Freitas (Bahia), 9 apresentaram-se em desacordo com as normas admitidas, sendo que de 80 amostras coletadas, 2 resultaram em positividade para coliformes totais, 5 para coliformes termotolerantes e 3 apresentaram a presença dos dois grupos (coliformes totais e termotolerantes).
A contagem de bactérias heterotróficas é amplamente utilizada como indicador da qualidade da água para consumo humano. Foi constatado no presente estudo que duas escolas apresentaram contagem elevada para estes micro-organismos. De acordo a legislação vigente, o valor não deve exceder o de 500 UFC/ 100mL (BRASIL, 2011). Sabioni e Silva (2006) ressaltam que as bactérias heterotróficas são encontradas naturalmente na água e enfatizam a importância do controle de sua densidade, pois em contagem elevada podem causar riscos à saúde do consumidor, uma vez que podem atuar como patógenos secundários.

O Ministério da Saúde prevê valores aceitáveis de pH entre 6,0 e 9,5 para água de consumo humano. Para este parâmetro, apenas uma escola apresentou inadequação, com o valor abaixo do preconizado. É importante a quantificação deste para águas destinadas ao consumo humano por ser um fator preponderante na solubilização de várias substâncias. Valores fora da faixa 
recomendada podem alterar o sabor da água e contribuir para a corrosão dos sistemas de distribuição (SPERLING, 1996).

Em 4 escolas monitoradas, o teor de cloro das amostras provenientes das torneiras de cozinhas ficou abaixo do mínimo preconizado pelo Ministério da Saúde, ou seja, inferior a $0,2 \mathrm{mg} / \mathrm{L}$. Entretanto para 2 instituições, estes valores apresentaram-se elevados em amostras coletadas de torneiras externas.O cloro e seus derivados têm contribuído para o controle das doenças de origem hídrica, atuando como fator de prevenção contra contaminações (MACÊDO, 2004).

Das escolas com resultados reprovados, 3 localizam-se no meio rural e apresentam poços artesianos como fonte de abastecimento, demonstrando a necessidade de suprimento de água potável para esse público. Num estudo realizado no Rio de Janeiro, Freitas et al. (2001) obteve mais de $50 \%$ das amostras de água de poço contaminadas por coliformes fecais em duas das áreas estudadas.

Camargo et al (2009) ao analisar água proveniente de poços no município de Carlinda (MT) obteve resultados que revelaram um alto grau de contaminação dos poços nas duas estações pluviométricas, sendo que o índice de contaminação por coliformes totais foi de $100 \%$ em todas as coletas. Em relação a Escherichia coli, foi observado um maior índice de contaminação no período chuvoso (91\%), em relação ao período da seca (79\%). A contagem total de bactérias aeróbias mesofílicas seguiu o mesmo padrão observado para E. coli.

Os resultados apontam, portanto, falhas na localização, limpeza e conservação dos reservatórios já que muitas das vezes a recontaminação acontece devido ao manuseio inadequado. Segundo Macêdo (2004), a limpeza dos reservatórios deve ser realizada semestralmente para que se proporcione melhor qualidade da água.

Numa pesquisa que avaliou a qualidade da água de abastecimento de 18 escolas de um município do Rio de Janeiro, verificou-se em 4 escolas resultados insatisfatórios em todos os pontos de coleta, sendo a contaminação atribuída a falta de limpeza e conservação dos reservatórios (FERNANDES 2007).

Conforme Brasil (2006), o tratamento da água em si não garante a manutenção da condição de potabilidade, podendo ocorrer contaminação entre o tratamento, distribuição e consumo.

Ao término das análises, foram elaborados laudos com os resultados e estes foram encaminhados as instituições de ensino. Realizaram-se também orientações referentes á forma adequada de manutenção e higienização dos reservatórios e bebedouros objetivando-se a melhoria da condição microbiológica da água. 


\section{CONCLUSÃO}

Pode-se detectar que uma parcela significativa das amostras de água analisada apresentou-se insatisfatória sendo que 14\% das amostras tiveram seus resultados reprovados do ponto de vista microbiológico. Estas não atendiam aos padrões de potabilidade representando assim, uma fonte de riscos para a comunidade escolar.

A água de consumo das instituições com resultados reprovados pode expor a comunidade escolar a riscos para a saúde, por meio de doenças de veiculação hídrica.

Assim, é necessário um acompanhamento para manutenção da higiene e controle microbiológico dos reservatórios de água desses locais, além da adoção de providências de caráter preventivo e corretivo tais como tratamento da água, limpezas periódicas e manutenção dos reservatórios, filtros e bebedouros.

Em relação á água de fonte subterrânea deve-se priorizar o monitoramento, além da observação de fatores que podem estar comprometendo a qualidade desta como a proximidade com esgoto doméstico e resíduos sólidos, além do contato com animais.

\section{REFERÊNCIAS BIBLIOGRÁFICAS}

BRASIL. Portaria 2914, 12 de dezembro de 2011: Procedimentos de controle e de vigilância da qualidade da água para consumo humano e seu padrão de

potabilidade. Ministério da Saúde, Brasília, 39, 2011.

BRASIL. Ministério da Saúde. Secretaria de Vigilância em Saúde. Inspeção sanitária em abastecimento de água, Brasília, p84, 2006.

CAMARGO , M. F. et al.; Avaliação qualitativa da contaminação microbiológica das águas de poços no município de Carlinda - MT . Semina: Ciências Biológicas e da Saúde, Londrina, v. 30, n. 1, p. 77-82, jan./jun. 2009.

\section{CASALI et al.,Qualidade da água para} consumo humano ofertada em escolas e comunidades rurais da região central do rio grande do sul. 2008. 173f. Dissertação de Mestrado (Área de Concentração em Processos Químicos e Ciclagem de Elementos) - Universidade Federal de Santa Maria, Santa Maria, 2008.

CAUBET, Cristian Guy. A Água, a lei, a política. Ministério do Meio Ambiente. Curitiba: Jurua, 2006.

CRUZ, J.B.F.; CRUZ, A.M.; RESENDE, A. Análise microbiológica da água consumida em estabelecimentos da educação infantil da rede pública do Gama, Distrito Federal.

Sabios: Revista Saúde e Biologia., v.4, n.1, p.21-23, 2009. 
FERNANDEZ, A. T; SANTOS, V.C.

Avaliação de parâmetros físico-químicos e microbiológicos da água de abastecimento escolar, no município de Silva Jardim, RJ.

Revista Higiene Alimentar, São Paulo, v. 21, n. 154, 2007.

FRANCO, B. D. G. de M.; LANDGRAF, M. Microrganismos patogênicos de importância em alimentos. Microbiologia dos alimentos. São Paulo: Atheneu, cap. 4, p. 33-82, 2006.

FREITAS, M.B.; BRILHANTE, O.M.;

ALMEIDA, L.M. Importância da análise de água para a saúde pública em duas regiões do Estado do Rio de Janeiro: enfoque para coliformes fecais, nitrato e alumínio.

Cadernos de saúde pública, Rio de Janeiro, v.17, n. 3, p. 651-660, 2001.

GUILHERME, E.F.M.; SILVA, J.A.M.;

OTTO, S.S. Pseudomonas aeruginosa como indicador de contaminação hídrica. Revista Higiene Alimentar, São Paulo, v.14, n.76, p.43- 46, 2000.

JUNIOR, Araujo Olimpio. Consciência sobre a Água. Disponível em: $<$ http://www.uniagua.org.br/public_html/web site/default.asp?tp=3\&pag=trabalhos.htm \# consciencia >. Acesso em 19 de fev. 2007.
MACÊDO, J. A. B., Águas e Águas. 2.ed.São Paulo:Varela, p505.462, 2004.

MICHELINA, A. de F.; BRONHAROA, T. M.; DARÉB, F.; PONSANOC, E. H. G. Qualidade microbiológica de águas de sistemas de abastecimento público da região de Araçatuba, SP. Revista Higiene Alimentar, São Paulo, v. 20, n. 147, p. 90-95, dez. 2006.

NETO, A. F. et al. Avaliação da qualidade da água potável de escolas públicas do Recife, PE. Revista Higiene Alimentar, São Paulo,v.20, n.139, 2006.

ROCHA, E. S. et al.;Análise microbiológica da água de cozinhas e/ou cantinas das instituições de ensino do município de Teixeira de Freitas (BA). Revista Baiana de Saúde Pública, v.34, n.3, p.694-705 jul./set. 2010.

SABIONI, J.G.; SILVA, I.T. Qualidade microbiológica de águas minerais comercializadas em Ouro Preto, MG. Revista Higiene Alimentar, São Paulo, v. 20, n. 143, p. 72-78, ago. 2006.

SCHAZMANN, R. D.; MENONCIN, F.; ELPO, E. R. S.; GOMES, E. C. Avaliação da qualidade bacteriológica da água consumida no Campus III (Jardim Botânico) da Universidade Federal do Paraná, Curitiba, 
Brasil. Visão Acadêmica, Curitiba. 9(2): 65-

70, 2008.

SERRA, C. L. M.; et al. Qualidade

microbiológica da água de escolas públicas do

município de Rosário, MA. Revista Higiene

Alimentar, São Paulo, v. 26, n. 208/209, p.

145-149, mai/jun. 2012.

SILVA, N.; et al. Manual de métodos de análises microbiológicas de alimentos e

água. $4^{\mathrm{a}}$ ed. São Paulo, Livraria Varela, 2010.

SILVA, F. C., Abastecimento da Água-

Importância da Água em Saúde Pública

(2006). Saneamento Básico-Portal de Saúde

Pública. Disponível em:

http://www.saudepublica.web.pt/06-

SaudeAmbiental/061-

Aguas/AbastecimAgua_texto.htm. Acesso em

11 de outubro de 2012.

SPERLING, M.V. Introdução á qualidade das águas e ao tratamento de esgotos. 2 ed. Belo Horizonte: Departamento de engenharia Sanitária e Ambiental- UFMG, 1996. v.1

cap1,p.11-50. 